\title{
MORPHOLOGIC RESPONSE OF BEACHES AND TIDAL INLETS TO HURRICANE IRMA IN SOUTHWEST FLORIDA, USA
}

\author{
Mohamed Dabees, Humiston \& Moore Engineers, Naples, Florida, md@humistonandmoore.com.
}

\section{BACKGROUND}

Hurricane Irma was a major Hurricane in the 2017 tropical season that reached category 5 and caused catastrophic damage in parts of the northeastern Caribbean and the Florida Keys. Irma was the strongest observed storm and the most intense in the Atlantic since 2005. Irma developed on August 30, 2017 near the west African coast then intensified into a hurricane on the SaffirSimpson scale within one day. Irma became a major storm at Category 3 hurricane On September 5, 2017 then reached its peak of Category 5 hurricane with intensity of $185 \mathrm{mph}(295 \mathrm{~km} / \mathrm{h})$ winds. Irma was a Category 4 hurricane, before making landfall on The Florida Keys and was a major Category 3 by the time it made a second Florida landfall on Marco Island and Naples in Southwest Florida on Sunday September 10, 2017. Irma weakened to a category 2 hurricane later that day as it tracked along the Florida peninsula. This paper discusses morphologic responses to the storm in Southwest Florida where Irma made landfall at Marco Island and Naples. FDEP (2018) provides documentation of the post-storm beach conditions and coastal impact of Hurricane Irma throughout the state of Florida, This paper focuses on case studies in Southwest Florida.

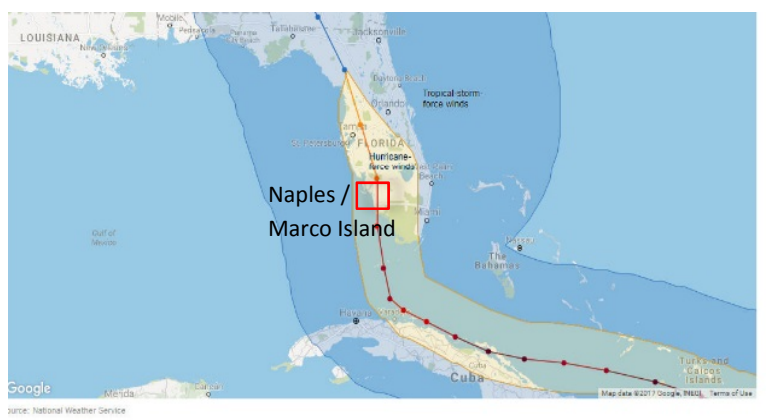

Figure 1 - Hurricane Irma Track and study area location

\section{STORM FORCINGS AND STUDY AREA}

Irma made its landfall on Florida's mainland on Marco Island south of Naples as a major hurricane then tracked north along southwest Florida (Figure 1). The storm track and wind circulation influenced water levels and waves with high intensity and varying conditions over a relatively short time. Ahead of the storm passing a given location, hurricane force winds pushing water offshore pushed water out of bays and estuaries approximately $1 \mathrm{~m}$ below still water levels. As the storm eye passed, the wind direction reversal caused the water levels to surge to over 1.5 meters above still water levels. This rapid change in water levels occurred over approximately 3 hours. The waves accompanied by the onshore storm surge phase added to the forcings affecting the beaches, inlets and estuaries that make up the coastal system of southwest Florida. Figure 2 shows the recorded water levels at
Naples with comparison to predicted water levels due to astronomical tide only.

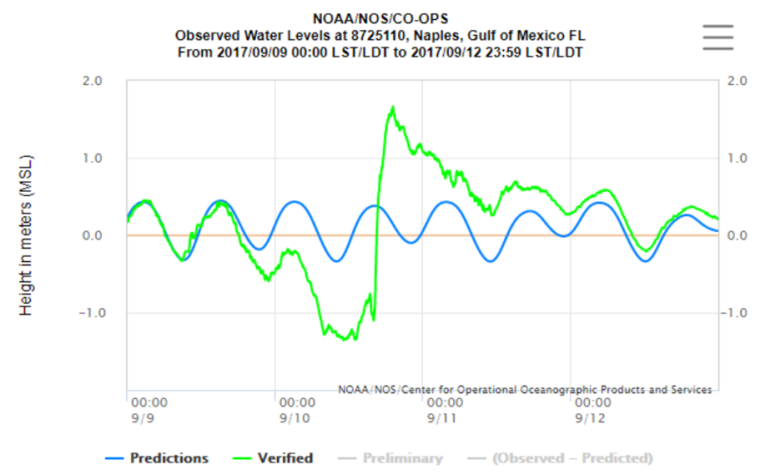

Figure 2 -Water levels and storm surge during Hurricane Irma

\section{STORM EFFECTS ON BEACHES}

Post storm observations and data from active monitoring programs along the study area of Marco Island and Naples indicated the morphologic response due to the storm surge and waves on beaches and inlets. General trends included beach and dune erosion with sand over wash landward into dune vegetation, coastal lagoons and estuaries. Figure 3 shows an example for the sand spit along the north end of Marco Island. The survey data and aerial photos indicated a landward migration of the sand spit of over 15 meters and sand over wash on the lagoon side of the spit of over 20 meters. The beach profiles comparisons shown in the figure quantifies the scale of the morphologic change in this area.
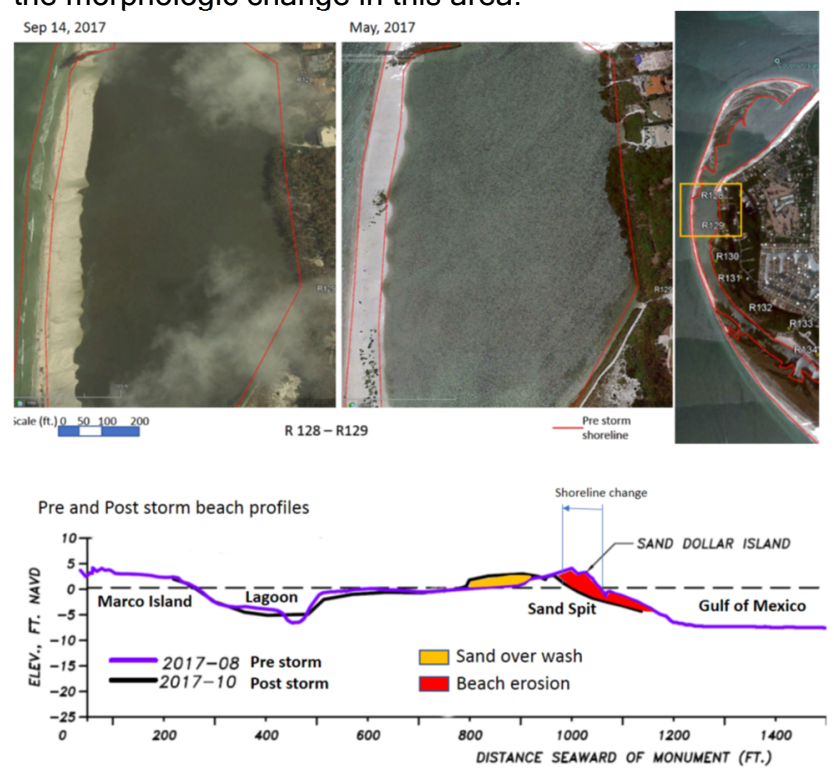

Figure 3 - Shoreline positions and profile change at the north part of Marco Island, Florida. Pre and post hurricane Irma 


\section{STORM EFFECTS ON TIDAL INLETS}

The analysis included hydraulic and morphologic data collected pre and post hurricane Irma. Tidal inlets were subjected to significant over wash with high sediment concentration coupled with rapid flow due to the high fluctuations of water levels.

The morphologic response was related to geographic configuration and size of the tidal inlet. The analysis included data collected on two different inlets in same region, a relatively large inlet and a small inlet in southwest Florida. The pre and post measured data indicate that the storm effects were more significant at relatively smaller inlets where the inlets and morphologic features are more event driven than large morphologic systems.

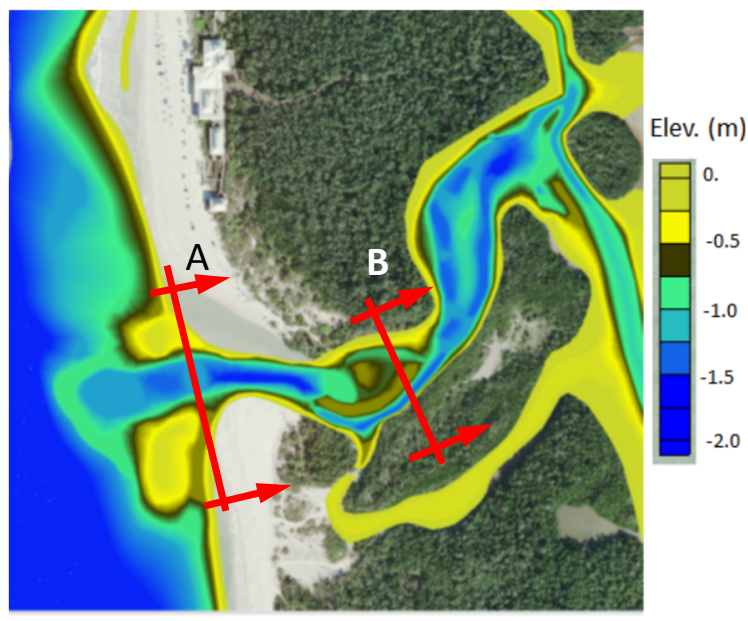

Pre-Irma (August 2017 conditions)

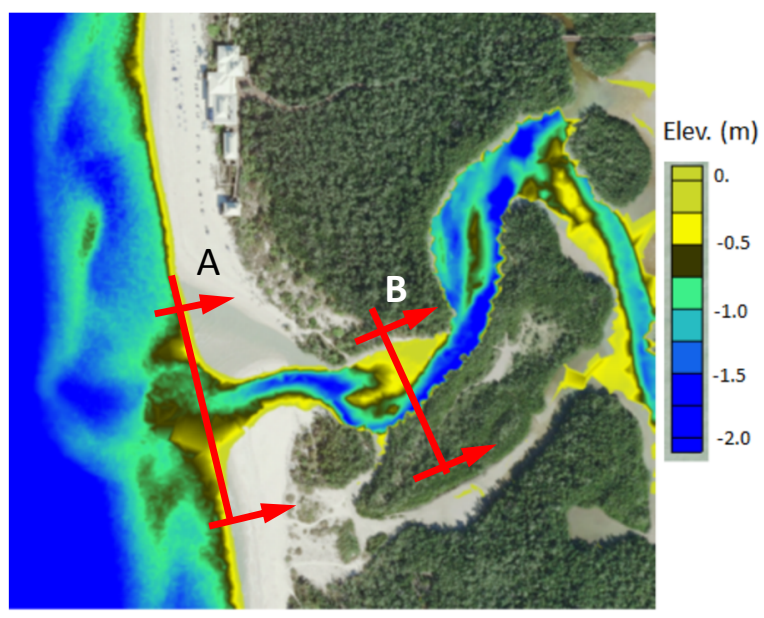

Post-Irma (September 2017 conditions)

Figure 4 - Inlet morphology pre and post Irma at Clam Pass

Figure 4 shows the inlet morphology pre and post Irma for Clam Pass in Naples Florida. Clam Pass is a small wave dominated inlet on the southwest coast of Florida that provides a tidal connection to 500 acres of wetland preserve. The relatively small tidal prism for Clam Bay provides critical balance between tidal energy and littoral process at the inlet channel. This affects the inlet hydraulic efficiency over time, especially when littoral transport rates are high due to periods of high wave energy or following major storm events. Maintenance dredging is done every few years to avoid inlet closure and maintain the tidal flow through the natural preserve system. As a small tidal inlet, Clam Pass exhibited more significant morphologic response to Hurricane Irma than larger inlets in the region. Figure 4 shows the measured bathymetry one month before Hurricane Irma (August 2017) and one week post storm (September 2017). Hydrodynamic forcing due to changes in water levels provided enough flow through the inlet to maintain such a small inlet open. As shown in Figure 3 above, water levels fluctuation exceeding $2.5 \mathrm{~m}$ range in a system where the astronomical tide is less than $1 \mathrm{~m}$ on an average tide. During the storm, strong current due to rapid change in water levels maintained flow channeling through wave driven sand deposition in the inlet channel and flood shoal areas. The morphologic response to these processes included migration and meandering channels that scoured around the deposition areas. Figure 5 shows cross sections at the channel and flood shoal areas.
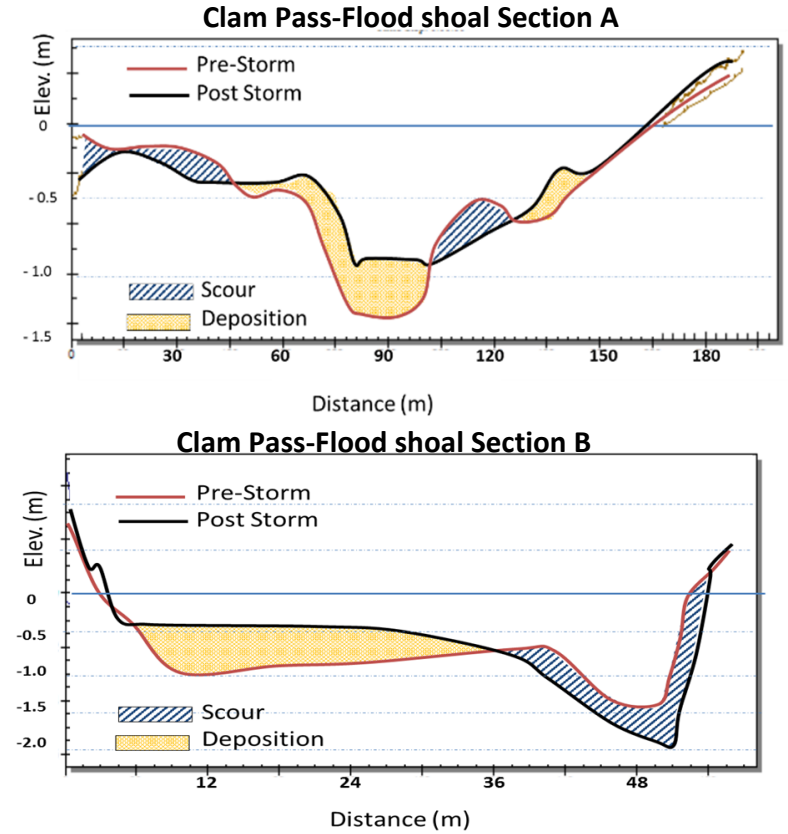

Figure 5- Cross-sections of inlet morphology pre and post Irma at Clam Pass.

The post storm data also indicated morphologic changes beyond the limits of the typical active ebb and flood shoal areas of this tidal inlet. The pre and post storm data included modeling and analysis of the typical conditions with comparison to post Hurricane Irma's conditions. The analysis was used to asses short term storm response and evaluation of potential longterm effects on the beach and inlet evolution in the study area.

\section{REFERENCES}

FDEP (2018) Hurricane Irma Post-Storm Beach Conditions and Coastal Impact in Florida. Florida Department of Environmental Protection. Technical Report 108p https://floridadep.gov/sites/default/files/IRMA Poststorm Report.pdf 